\title{
Transcatheter coil embolisation of a pulmonary arteriovenous malformation in a neonate
}

\author{
R Mark Grady, Angela M Sharkey, Nancy D Bridges
}

\begin{abstract}
Pulmonary arteriovenous malformations (PAVM) are a rare cause of cyanosis in neonates. A large PAVM in a neonate was successfully occluded by transcatheter embolisation. At six months follow up the PAVM was undetectable and no new lesions were found. Transcatheter embolisation should be considered as the primary treatment for a PAVM in a child of any age.
\end{abstract}

(Br Heart f 1994;71:370-371)
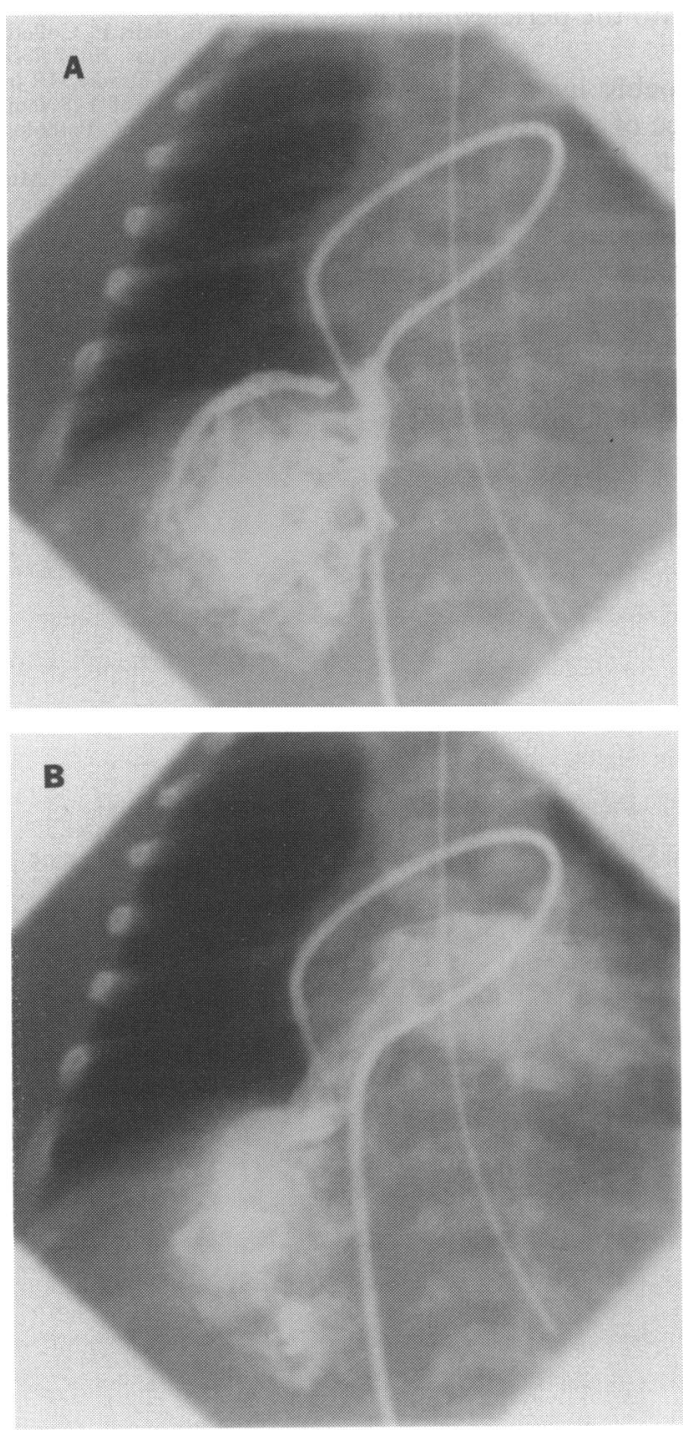

Figure 1 Angiogram showing balloon occlusion of the right pulmonary artery in a patient with a large pulmonary arteriovenous malformation. (B) Venous phase showing drainage of the pulmonary arteriovenous malformation into the right lower pulmonary vein.
Pulmonary arteriovenous malformations (PAVM) are a rare cause of cyanosis in neonates. In all previously reported cases surgery was offered as the primary treatment. ${ }^{1}$ We report the successful primary treatment of a PAVM in a newborn by transcatheter coil embolisation.

\section{Case report}

After an uncomplicated labour and delivery, a full term, $2.7 \mathrm{~kg}$ infant was described in the delivery room as "ashen grey". Examination showed no evidence of respiratory distress or congestive heart failure. When placed in $100 \%$ oxygen, the transcutaneous oxygen saturations were $80 \%-85 \%$ and the $\mathrm{PO}_{2}$ was $42 \mathrm{~mm} \mathrm{Hg}$. Because of increasing cyanosis the child was intubated and transferred to our institution on the third day after birth.

Cardiac examination found normal heart sounds with no murmur. Lung fields were clear with no bruits. There was no hepatomegaly. Pulses and perfusion were normal. No telangiectatic lesions were noted. The child's cyanosis did not improve with mechanical ventilation and neuromuscular blockade.

A chest $x$ ray film showed cardiomegaly, oligaemic lung fields, and a right lower lobe opacity. Echocardiography showed bidirectional flow at the foramen ovale. Both ventricles were dilated. On both the subcostal and high parasternal views an echodense mass with multiple areas of vascular flow was seen posterior and inferior to the right pulmonary artery in the hilum of the right lung. Doppler echocardiography in these small vessels showed continuous flow. The right lower pulmonary vein was dilated. A diagnosis of a PAVM was made.

On the fifth day after birth the child underwent cardiac catheterisation. The right heart pressures were normal, with a right pulmonary artery pressure of $33 / 12 \mathrm{~mm} \mathrm{Hg}$, mean $21 \mathrm{~mm} \mathrm{Hg}$. During intubation and in $100 \%$ oxygen, the arterial $\mathrm{Po}_{2}$ was $27 \mathrm{~mm} \mathrm{Hg}$ with a saturation of $77 \%$. When the right pulmonary artery was occluded by a balloon the arterial $\mathrm{PO}_{2}$ rose to $256 \mathrm{~mm} \mathrm{Hg}$. An angiogram of the right pulmonary showed a large, single PAVM with two afferent vessels from the right lower lobe pulmonary artery, and one large efferent vessel draining to the right lower pulmonary vein (fig 1). The right pulmonary artery was otherwise normal. Eight Gianturco steel coils were placed in the afferent vessels of the PAVM. Repeat angiography 


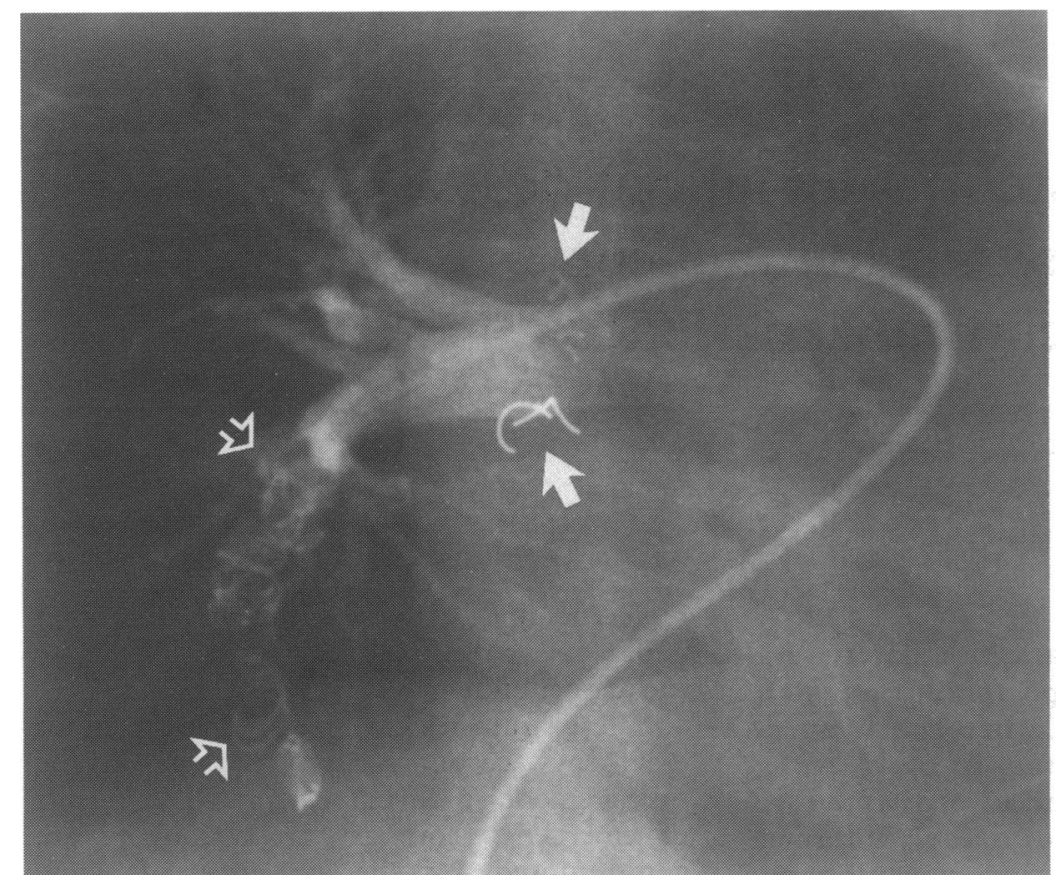

Figure 2 Angiogram of right pulmonary artery showing occlusion of the pulmonary arteriovenous malformation (open arrows) with coils and also coils in the bronchial collaterals (closed arrows). present in the second decade of life with cyanosis and dyspnoea. ${ }^{2}$ Of the 11 reported neonatal cases, including this one, 10 presented with cyanosis within the first 72 hours after birth. ${ }^{1}$ The other infant presented at three weeks of age with dyspnoea from a hemothorax after rupture of the PAVM. ${ }^{3}$

Up to half of the adult patients with PAVMs have multiple lesions, especially those with hereditary haemorrhagic telangiectasia (Osler-Weber-Rendu syndrome). ${ }^{2}$ All 11 of the neonates with PAVM had a single lesion, usually in the right or left lower lobe. The development of new lesions has been reported to occur in older children ${ }^{4}$; however, none of the previous surviving neonatal cases have reported follow up. Our patient had no new PAVM at six months. This uncertain natural history emphasises the need for subsequent evaluation in all infants diagnosed with PAVM.

In the 10 previously reported neonatal cases, surgical resection was offered as the primary treatment and in most cases (seven of 10) resulted in a complete lobectomy. Transcatheter embolisation of PAVM has proved to be safe and effective in older children and adults ${ }^{25}$; our case shows that this technique can be successfully used in neonates as well. Benefits include avoiding a thoractomy, preserving normal lung tissue that otherwise might be excised, the potential to identify and occlude multiple, bilateral PAVMs in one procedure, and the ability to easily repeat the procedure should new lesions develop. Transcatheter embolisation should be considered as the primary treatment of PAVM in a child of any age. room air. Catheterisation showed normal haemodynamic function. In room air the arterial $\mathrm{Po}_{2}$ was $96 \mathrm{~mm} \mathrm{Hg}$ with a saturation of $96 \%$. Angiography showed no flow in the PAVM (fig 2) and normal right and left pulmonary arteries. No other PAVM were seen in either lung. Two $2 \mathrm{~mm}$ bronchial collaterals supplying the right lower lobe were embolised by coils.

\section{Discussion}

Congenital PAVMs are rarely diagnosed in neonates. Patients with PAVM typically
1 Allen SW, Whitfield JM, Clarke DR, Sujansky E, Wiggins JW. Pulmonary arteriovenous malformation in the newborn: a familial case. Pediatr Cardiol 1993;14:58-61.

2 Burke CM, Safai C, Nelson DP, Raffin TA. Pulmonary arteriovenous malformations: a critical update. Am Rev Respir Dis 1986;134:334-9.

3 Milovic I, Oluic D. Congenital pulmonary arteriovenous fistula with haemothorax in a neonate. Zeitschrift fur Kinderchirurgie 1989;44:109-10.

4 Knight WB, Bush A, Busst CM, Haworth SG, Bowyer JJ, Shinebourne EA. Multiple pulmonary arteriovenous fistulas in childhood. Int $f$ Cardiol 1989;23:105-16.

5 Marin-Garcia J, Lock JE. Catheter embolization of pulmonary arteriovenous fistulas in an infant. Pediatr monary arteriovenous
Cardiol 1992;13:41-3. 